\title{
Informational Texts Comprehension with Collaborative Strategic Reading Model
}

Manuscript ID:

EDU-2021-09044234

Volume: 9

Issue: 4

Month: September

Year: 2021

P-ISSN: 2320-2653

E-ISSN: 2582-1334

Received: 28.06.2021

Accepted: 07.08.2021

Published: 01.09.2021

Citation:

Semercioglu, Muhammed

Serhat, et al. "Informational

Texts Comprehension with

Collaborative Strategic

Reading Model." Shanlax

International Journal of

Education, vol. 9, no. 4,

2021, pp. 445-59.

DOI:

https://doi.org/10.34293/

education.v9i4.4234

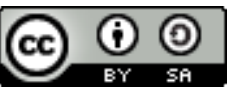

This work is licensed under a Creative Commons Attribution-ShareAlike 4.0 International License

\author{
Muhammed Serhat Semercioglu \\ Gumushane University, Turkey \\ https://orcid.org/0000-0001-9210-4779
}

Kaya Tuncer Çağlayan

Turkey

iD https://orcid.org/0000-0001-5655-7906

\author{
Kasım Kıroğlu \\ Turkey \\ https://orcid.org/0000-0001-5655-7906
}

\begin{abstract}
The main purpose of this study is to examine the effect of teaching through the "Collaborative Strategic Reading (CSR) Model" on the reading comprehension skills at primary fourth grade. As a consequence, it was concluded in the study that the pre-test means were close to each other in the experimental and control group and that the experimental group had a higher mean than the control group in the post-test mean scores. Moreover, no significant difference was obtained between the experimental and control groups regarding the pre-tests. Still, a significant difference was obtained in favour of the experimental group for the post-tests. On the other hand, whereas it was determined that there was no significant difference between the experimental and control group for the pre-tests of Reading Comprehension and Main Theme Determination scales, there was a significant difference in favour of the experimental group for the post-tests and gain levels. It was also concluded that the value $p$ which corresponded to $Z=0,58$ in the Pearson Product-Moment equation was $0.082(p>0,05)$, and considering that the result was not significant, the pre-test/ post-test prediction level was not significant, and the power degree of the correlation between them did not present a significant difference.
\end{abstract}

Keywords: Reading comprehension, Collaborative strategic reading, Informational text, Primary students, Reading model, Comprehension skills

\section{Introduction}

The fundamental assumption about the concept of reading is the opinion that "children first learn to read, then they read to learn (Repaskey et al., 2017, p. 4). Initially, even though it is widely believed that young children prefer fairy-tale texts (Bryan, Smith, \& Burrows, 2007), the evidence that this is not true is increasing day by day. It has been observed that the developmentally appropriate informative texts, which especially develop the curiosity of young children, are now preferred more by children (Repaskey et al., 2017, p.4).

In a present world called as "information age", the increase in need of students to obtain information and the increase in the frequency of the use of such texts in reading comprehension tests that are becoming widespread is considered as the evidence of this change in preference (Balc1, 2016, p. 94). The collaborative strategic reading model is planned to overcome the problem of understanding informative texts through "reciprocal learning". 
Reciprocal learning refers to preview to get an idea about the concept to be learned, asking questions about the idea that the text is trying to convey, making explanations for unknown information, and summarising the main points. The basis of the Collaborative Strategic Reading Model is conducted through the methods to be implemented before, during, and after reading. "Preview method" before reading, "Click and Cluck method" during reading, "Learning the essence method", and "Text review method" after reading are utilised in this respect.

Preview method should be used before starting to read the text to get prior knowledge about the text, establish a connection between the topic of the day and the previous subject learned, make predictions about the topic of that lesson, and determine the purpose of reading (Klingner, Vaughn, Boardman and Swanson 2012, p.25). The name of the finding word method is the Click and Cluck method. This method is applied when reading the text. In the Learning the essence method, the students should define the most important point of the text (people, places, and activities). While making these definitions, the students are expected to re-express what they understand through their sentences, first paragraph by paragraph, and finally until they get a single sentence. The Text review method is designed to assist the students in reviewing the information they have learned from the text (Yen, 2009, p. 8). The main purpose of this method is to review the text for the last time, summarise the text, generate some questions, and check whether the whole text is understood or not.

\section{Research Design}

This research is a study that examines the effect of traditional teaching methods on reading comprehension and main idea determination levels of the fourth-grade students through the Collaborative Strategic Reading Model and represents the descriptive, sequential mixed model in which the quantitative and qualitative research methods are applied together. Research with mixed-method makes explanations by collecting quantitative and qualitative data and analysing them together in the process. It is understood in research with a mixed method that the researcher should use the quantitative research at a predetermined time and the qualitative research at a later time (Creswell, 2003). Therefore, in another saying, the researchers initially collect and analyse the quantitative data, and then they collect the qualitative data to complete these data (Büyüköztürk, 2016).

The matched design with pre-test and posttest control groups, one of the quasi-experimental designs, was applied in the quantitative part of the descriptive, sequential mixed model. Two groups are available in this design: One is used as the experimental group and the other as the control group. The required measurements are made in both groups before and after the research (Karasar, 2011, p.97). As a result of these measurements made in the design, two of the available groups are tried to be matched in terms of certain variables (Büyüköztürk, 2016).

The data were collected through the interview technique, one of the data collection techniques, in the qualitative part of the study. After the quantitative processes were completed, the opinions of the students in the experimental group and the classroom teacher about teaching informative texts through the Collaborative Strategic Reading Model were taken through the interview forms that were previously prepared. In the qualitative analysis phase, the qualitative data consisting of the opinions of the experimental group students and the classroom teacher about the practice were described and analysed according to the answers given to the questions in the forms by making direct quotes from the opinions of the participants.

Whereas the reading comprehension and main idea determination scores of the students were the dependent variables in the study, the teaching based on the Collaborative Strategic Reading Model applied to the experimental group and the current program applied to the control group were the independent variables. The effect of independent variables on dependent variables was determined through the different teaching methods applied to the students.

\section{The Population and Sample of the Research}

The population of the study comprises of the fourth-grade students in primary schools affiliated 
with the Ministry of National Education in the central district of Gümüşhane. The most important reason for selecting the fourth-grade students for the population of the research is that they start to read more informative texts as of the fourth grade.

While selecting the study sample, the purposeful sampling belonging to the non-random sampling method was chosen in the most general sense. To determine the sample of the study, initially, some interviews were conducted with the principals and 4th-grade teachers of the schools in Gümüşhane city centre about the number of classes in the schools, the number of students, and their willingness to do the research. While determining the experimental and control groups, a reading comprehension test consisting of 20 questions was applied to 5 classes in the selected school, and the demographic information of all classes was obtained. The two branches with the closest test results and demographic information to each other were randomly determined as the "experimental and control" group. Whereas the experimental group comprising the sample consists of 27 students, the control group comprises 25 students.

\section{Data Collection Instruments}

Within the scope of the study, the "Reading Comprehension Test in Informative Texts" was utilised to reveal the reading comprehension status of the students, and the "Main Idea Determination Test in Informative Texts" was applied to reveal the status of determining the main idea and subject of the text.

\section{The Selected Texts}

The texts used throughout the research were selected from the magazines "Bilim Çocuk" and "TSE Öncü Çocuk" that are available on the website www.eba.gov.tr and prepared by the Head Council of Education and Morality. Utmost attention was paid in determining the texts to reflect the characteristics of the informative text structure, to be appropriate to the level, interests and needs of the student, and to be written in a clear and understandable language. A total of 15 texts, three in each informative text type, were examined by nine people, three of whom had a doctorate in reading, three of whom were
Turkish teachers, and three of whom were classroom teachers. As a result of the expert opinions, five texts, one in each type of informative text, with the highest score, were used in the research. The texts to be applied; These Passages are for Wild Animals (Problem Solving) .88, Do You Want to Take Selfie (Description) 1.00, These Houses are on Water (Cause-Effect) .77, Hours (Ranking) 1.00 and Istanbul's Seagulls (Comparison) 1.00 were calculated.

\section{Reading Comprehension Test}

The questions generated within the scope of the research to determine the reading comprehension levels of the students were prepared using the relevant outcomes specified in the Primary School Turkish Teaching Program. From the program, 8 measurable outcomes related to informative texts were selected while preparing for the reading comprehension test. First of all, a reading comprehension test with 59 questions consisting of multiple-choice items and suitable for the selected outcomes was prepared for the reading comprehension test.

Reading comprehension test was examined by a team of seven experts, two of whom were the experts in the field of assessment and evaluation, two of whom were classroom teachers, and three of whom were Turkish teachers. As a result of the examinations, the reading comprehension test was reduced to 52 questions. To conduct a pilot study, the reading comprehension test with 52 questions was applied to 62 students studying in three different 4th grade classes in a public school in Aksaray. The behaviours of the students, the duration of the test, the inconveniences in the outputs, and the opinions of the students were noted throughout the test. The difficulty and distinctiveness indices of each item desired to be measured were calculated at the end of the pilot study. As a result, nine questions that were below the standard in the reading comprehension test according to the item difficulty and distinctiveness indices were omitted from the test, and a "Reading Comprehension Test" with 44 questions in five parts (description, ranking, comparison, cause-effect and problem solving) was obtained. 


\section{Main Idea Determination Test}

The questions prepared for the main idea determination test were designed to measure the five outcomes specified in the Primary School Turkish Teaching Program. A test with 54 questions consisting of multiple-choice and open-ended items and suitable for the determined outcomes was prepared for the main idea determination test. The test with 54 questions was examined by a team of seven experts, two of whom were experts in the field of assessment and evaluation, two of whom were classroom teachers, and three of whom were Turkish teachers. As a result of the examinations, the main idea determination test was reduced to 49 questions.

The test was first applied to a group of 62 students. The difficulties the students encountered while solving the questions, the duration of the test and the difficult parts were observed in this pilot study. As a result of this observation and test, six questions that were below the standard in the reading comprehension test according to the item difficulty and distinctiveness indices were excluded from the test, and the "Main Idea Determination Test" with 43 questions in five parts (description, ranking, comparison, cause-effect and problem solving) was obtained.

\section{Practice}

After the measurement instruments required to be used throughout the practice were generated, the practice phase was started. After the pre-tests were applied to all groups, the lessons by the Collaborative Strategic Reading Model were applied to the experimental group for 6 sessions, 4 lessons per session. In the control group, the lessons with the same texts were applied according to the traditional teaching method of the 2017 Turkish Program. The researcher personally taught the lessons to the experimental and control groups throughout the practices.

The Collaborative Strategic Reading Model, which was developed by Klingner and Vaughn (1998), started to be taught in 2004, and originally called "Collaborative Strategic Reading" was applied to the experimental group and wanted to be tested. The model generally includes before, during, and after reading methods. These methods were applied through the specified texts. The schedule and plan of the practice for the control group are the same as the experimental group. The lessons in the control group were conducted by the researcher by the traditional teaching method of the Turkish Teaching Program (2017). The selected texts are the same as those used in the experimental group. The lesson plans are also arranged according to the current system.

\section{Data Analysis}

Reading comprehension test and main idea determination test in informative texts were used as data collection instruments in the study. The data obtained were analysed through the SPSS 20.0 package program. Within the scope of the study, Kolmogorov-Smirnov and Shaphiro-Wilk tests were used to determine whether the score distributions of the Reading Comprehension Test were normally distributed, and the t-test was conducted to determine the significance of pre-test and post-test findings and gain scores. Likewise, Kolmogorov-Smirnov and Shaphiro-Wilk tests were applied to determine whether the score distributions of the Main Idea Determination Test were normally distributed, and the t-test was conducted to determine the significance of pre-test and post-test findings and gain scores.

To determine the significance between Reading Comprehension and Main Idea Determination levels and the significance level of significance, if any, Pearson product-moment correlation was determined for each test. Then Fisher $\mathrm{Z}$ test was applied according to these correlation values. Fisher $\mathrm{Z}$ test result was converted to $\mathrm{p}$ coefficient, and it was determined whether there was a significant difference between them. In addition, the square of the multiple correlations was taken to determine the significance of the difference, and the percentage value was obtained.

Semi-structured interview forms were prepared to obtain qualitative data. The questions in the interview form were supported with probe questions according to the flow of the interview. Through these probe questions, the participants were asked to detail their opinions. As a result, the obtained qualitative data were described by making direct quotations from the opinions of the participants. 


\section{Findings}

The mean scores, standard deviations, independent groups t-test, Pearson moments product, and Fisher $\mathrm{Z}$ test results obtained from the pre-test and post-test of the "Reading Comprehension Test" and "Main Idea Determination Test" of the students in the experimental and control groups were included for the specified sub-questions.

First of all, it was tested whether the test scores of the experimental and control group students belonging to the "Reading Comprehension Test" presented normal distribution or not. According to the obtained results, parametric tests were used to analyse quantitative data related to the comparison of the pre-test and post-test ( $p>0,05)$.

\section{Findings of the First Sub-Question}

The findings of the experimental group students who learnt the informative texts through the Collaborative Strategic Reading Model and the control group students to whom the traditional education was given (2017-2018 Academic Year
Turkish Teaching Program) were obtained for the first sub-question of "Is there a significant difference between the levels of reading comprehension for the informative text structures?"

Independent samples t-test was conducted to determine whether there is a significant difference between the reading comprehension pre-test scores before the practice and the reading comprehension levels of the experimental group students and the control group students for the informative text structures. According to the pre-test means of the control and experimental groups, it is observed that the results are very close to each other (experimental group $X=26,40$ and control group $X=26$ ).

Whether there is a significant difference between the reading comprehension levels of the experimental group students and the control group students in the post-test related to the informative text structures measured after the practice was tested for the independent samples through the t-test, and the results are presented in Table 1.

Table 1: Knowledge Levels of Reading Comprehension Post-test related to Informative Text Structures

\begin{tabular}{|c|c|c|c|c|c|c|c|}
\hline & Group & $\mathbf{N}$ & $\mathbf{X}$ & $\mathbf{S}$ & sd & t & p \\
\hline \multirow{2}{*}{ Post-test } & Experimental & 27 & 37,51 & 2,94 & \multirow{2}{*}{50} & \multirow{2}{*}{8,57} & \multirow{2}{*}{$0,000 *$} \\
\cline { 2 - 5 } & Control & 25 & 30,36 & 3,08 & & & \\
\hline
\end{tabular}

When Table 27 is examined, it is observed that reading comprehension post-test levels related to the informative text structures of the experimental group students $(X=37,51)$ measured after the practice are higher than the control group students $(X=30,36)$. As a result of the t-test testing whether this difference was statistically significant or not, it was understood that there was a significant difference $\left(\mathrm{t}_{(50)}=8,57 ; \mathrm{p}<0,05\right)$. This difference is in favour of the experimental group.

Whether there is a significant difference between the gain (post-test, pre-test score difference) levels related to the reading comprehension test of the experimental group and control group students participating in the practice was tested for independent samples through the t-test. The results are shown in Table 2.

Table 2: Findings related to Gain Level Scores of Reading Comprehension Test

\begin{tabular}{|c|c|c|c|c|c|c|c|}
\hline & Group & $\mathrm{N}$ & $\mathrm{X}$ & $\mathrm{S}$ & $\mathrm{sd}$ & $\mathrm{t}$ & $\mathrm{p}$ \\
\hline \multirow{2}{*}{$\begin{array}{c}\text { Gain } \\
\text { Level }\end{array}$} & Experimental & 27 & 11,88 & 3,96 & \multirow{2}{*}{50} & \multirow{2}{*}{8,58} & \multirow{2}{*}{$0,000 *$} \\
\cline { 2 - 5 }$* \mathrm{p}<0.05$ & Control & 25 & 4,28 & 2,05 & & & \\
\hline
\end{tabular}

When Table 28 is examined, it is concluded that the gain level (difference in post-test, pretest scores) for the reading comprehension test of the experimental group students measured after the practice $(\mathrm{X}=11,88)$ is higher than the control group students $(X=4,28)$. A statistically significant 
difference was found between the levels of the text structures of the experimental group students and the control group students measured after the practice $(p<0,05)$. This difference is in favour of the experimental group.

\section{Findings of the Second Sub-Question}

The findings of the experimental group students who learnt the informative texts through the Collaborative Strategic Reading Model and the control group students to whom the traditional education was given (2017-2018 Academic Year Turkish Teaching Program) were obtained for the second sub-question of "Is there a significant difference between the levels of main idea determination for the informative text structures?"

Whether the test scores of the experimental and control group students belonging to the "Main Idea Determination Scale" presented normal distribution was tested. It is observed that the scores obtained from the measurement instruments for the pre-test and post-test show a normal distribution $(p>0,05)$. According to these results, parametric tests were used to analyse quantitative data related to the comparison of pre-test and post-test.

Independent samples t-test was conducted to determine whether there is a significant difference in the informative text structures of the experimental group students and the control group students in the pre-test scores of the main idea determination scale conducted before the practice. According to the results, it is concluded that the means of the pre-test results of the control and experimental groups are quite close to each other (experimental group $\mathrm{X}=$ $21,81$ and control group $X=20,92)$. A statistically significant difference was not found between the experimental group students and the control group students in terms of determining the main idea about the informative text structure in the pre-test results before the practice $(\mathrm{t} 50=1,222 ; \mathrm{p}>0,05)$.

Whether there is a significant difference between the post-test levels of the main idea determination scale regarding the informative text structures of the experimental group students and the control group students measured after the practice was tested through the independent samples t-test, and the results are provided in Table 3 .

Table 3: Post-test Levels of Main Idea Determination Scale for Informative Text Structures

\begin{tabular}{|c|c|c|c|c|c|c|c|}
\hline & Group & N & X & S & sd & t & p \\
\hline \multirow{3}{*}{ Post-test } & Experimental & 27 & 35,70 & 2,14 & \multirow{2}{*}{50} & \multirow{2}{*}{17,74} & \multirow{2}{*}{$0,000 *$} \\
\cline { 2 - 5 } & Control & 25 & 23,76 & 2,69 & & \\
\hline
\end{tabular}

When Table 31 is examined, it is seen that the post-test levels of determining the main idea about the informative text structures of the experimental group students measured after the practice $(X=35.70)$ are higher than the control group students $(X=23.76)$. A statistically significant difference was found in the main idea determination levels about the text structures between the experimental group students and the control group students measured after the practice $(\mathrm{t} 50=1,222 ; \mathrm{p}<0.05)$. This difference is in favour of the experimental group.

Whether there is a significant difference between the gain (post-test, pre-test score difference) levels related to the main idea determination scale of the experimental group and control group students participating in the practice was tested for independent samples through the t-test. It is concluded that the gain level (difference in post-test, pre-test scores) for the reading comprehension test of the experimental group students measured after the practice $(\mathrm{X}=$ $13,70)$ is higher than the control group students ( $X$ $=3,00)$. A statistically significant difference was obtained between the experimental group students and the control group students in terms of the main idea determination levels about the text structures measured after the practice $(\mathrm{t} 50=1,222 ; \mathrm{p}<0.05)$. This difference is in favour of the experimental group.

\section{Findings of the Third Sub-Question}

In line with the third sub-question expressed as "Is there a meaningful correlation between reading comprehension and main idea test scores?" of the experimental group students who learn the 
informative texts through the Collaborative Strategic Reading Model, the findings and comments related to the pre-test and post-test scores of the experimental group is given below.

The correlation between the reading comprehension pre-test levels and the main idea determination pre-test scores of the experimental group students regarding the informative text structures measured before the practice was examined through the Pearson moments product correlation coefficient. The results are presented in Table 4.

Table 4: The Correlation between Reading Comprehension and Main Idea Determination Pre-test Scores for Informative Text Structures

\begin{tabular}{|l|l|l|l|l|l|l|}
\hline & & Tests & $\mathrm{N}$ & $\mathrm{r}$ & $\mathrm{p}$ & \\
\hline \multirow{2}{*}{ Pearson moments product } & \multirow{2}{*}{ Pre-test } & Reading Comprehension & 27 & \multirow{2}{*}{, $682 *$} & \multirow{2}{*}{0,01} & \\
\cline { 3 - 4 } & & Main Idea Determination & 27 & & \\
\cline { 3 - 4 } & & &
\end{tabular}

$*$ The $\mathrm{p}$-value for this correlation product is 0,01 .

According to Table 4, it is observed that there is a positive moderate significant correlation of 0.682 between the reading comprehension and main idea determination test scores of the experimental group students measured before the practice $(\mathrm{p} \leq 0.01)$. In another saying, as the pre-test reading comprehension scores of the students in the experimental group increase, the main idea determination pre-test scores also increase. The correlation scatters diagram of the correlation between reading comprehension and main idea determination pre-test scores for the informative text structures is as follows:

When the scatter diagram of the pre-test scores in Figure 1 is examined, it is observed that the correlation between the pre-test scores is linear.

The correlation between the reading comprehension post-test and the main idea determination post-test scores measured after the practice made to the experimental group students was examined through Pearson moments product. The results are provided in Table 5.

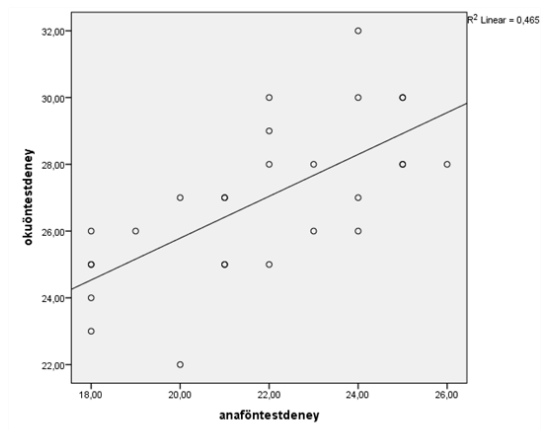

Figure 1: Pre-Test Scores Correlation Scatter Diagram

Table 5: The Correlation between Reading Comprehension and Main Idea Determination Post-test Scores for Informative Text Structures

\begin{tabular}{|l|l|l|l|l|l|}
\hline & & Tests & N & r & $p$ \\
\hline \multirow{2}{*}{ Pearson moments product } & \multirow{2}{*}{ Post-test } & Reading Comprehension & 27 & \multirow{2}{*}{$407 *$} & \multirow{2}{*}{0,05} \\
\cline { 3 - 4 } & & Main Idea Determination & 27 & & \\
\hline
\end{tabular}

$*$ The $\mathrm{p}$-value for this correlation product is 0,05 .

According to Table 5, it is concluded that there is a positive moderate significant correlation of 0.407 between the reading comprehension and main idea determination test scores of the experimental group students measured after the practice $(\mathrm{p} \leq 0.05)$. In other words, as the reading comprehension scores of the experimental group students measured after the practice increase, the main idea determination test scores also increase. The correlation scatters diagram of the correlation between reading comprehension and main idea determination post-test scores for the informative text structures is presented as follows: 


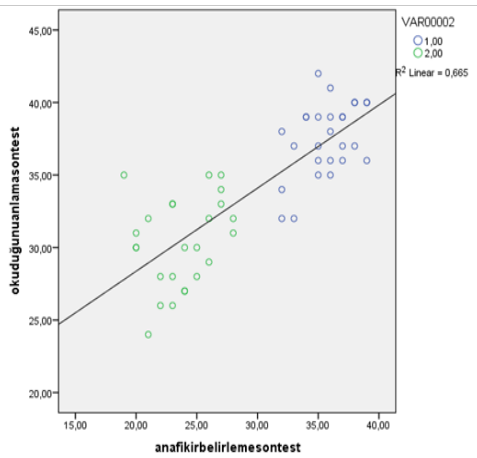

\section{Figure 2: Post-Test Scores Correlation Scatter Diagram}

When the scatter diagram of the post-test scores in Figure 9 is examined, it is seen that the correlation between the post-test scores is linear.

After providing all the assumptions regarding the linearity of the scatter diagrams, the values of the Fisher $\mathrm{Z}$ test were examined to understand whether the other assumption, the Pearson product-moment equation, is important and to compare the correlation coefficients. Fisher $\mathrm{Z}$ test is obtained through the following formula:

$$
Z_{r 1}=0.5 \operatorname{Ln}\left[\frac{1+r_{1}}{1-r_{1}}\right] \quad Z_{r 2}=0.5 \operatorname{Ln}\left[\frac{1+r_{2}}{1-r_{2}}\right] \text { and }
$$

When relevant values are placed;

$$
\begin{aligned}
Z & =\frac{\left(\mathrm{r}_{1}^{\prime}-\mathrm{r}_{2}^{\prime}\right)}{\sqrt{\left(1 /\left(\mathrm{n}_{1}-3\right)+1 /\left(\mathrm{n}_{2}-3\right)\right]}} \\
Z_{r 1} & =\mathbf{0 . 5} \operatorname{Ln}\left[\frac{1+0,682}{1-0,682}\right] \text {, thus } Z_{r 1}=\mathbf{0 . 5} \times \operatorname{Ln}\left[\frac{1,682}{\mathbf{0 , 3 2 8}}\right]
\end{aligned}
$$$$
\text { and consequently, } \boldsymbol{Z}_{r \mathbf{1}}=\mathbf{0 , 3 5 4} \text { is obtained. }
$$$$
Z_{r 2}=0.5 \operatorname{Ln}\left[\frac{1+0,407}{1-0,407}\right] \text {, thus } Z_{r 1}=0.5 \times \operatorname{Ln}\left[\frac{1,407}{0,593}\right] \text {, }
$$$$
\text { and consequently, } \boldsymbol{Z}_{r 2}=\mathbf{0 , 1 8 7} \text { is obtained. }
$$

Ultimately, to find the $\mathrm{Z}$ value;

$$
x=\frac{0,354-0,187}{\sqrt{\frac{1}{27-3}+\frac{1}{27-3}}}, \text { thus } x=\frac{0,167}{0,286},
$$

as a result, the $\mathrm{p}$-value corresponding to $\mathrm{Z}=0.58$ in the Pearson product of moments equation is at the level of $0.082(p>0.05)$. Based on the lack of significance in the result, it was concluded that the pre-test and post-test predictive levels were not significant and that the degree of strength of the correlation between them did not differ significantly (Von Eye \& Mun, 2005; Mendeş \& Karabayır, 2003; Eid, Gollwitzer \& Schmidt, 2011, p. 547).

\section{Findings of the Fourth Sub-Question}

In the direction of the fourth sub-question expressed in the form of "What are the opinions of the experimental group students and teachers about the informative text teaching practices with the Collaborative Strategic Reading Model?", the opinions of the experimental group students and their teachers about the practice were taken. So, the quantitative data collected during the practice process supported the qualitative data obtained through the interviews.

While conducting qualitative analysis, it is tried to understand such unobservable characteristics of individuals as their experiences, attitudes, thoughts, intentions, interpretations, mental perceptions, and reactions (Yıldırım \& Şimşek, 2008). There are different types of interviews: structured, semistructured, unstructured, ethnographic, and focus group (Büyüköztürk et al., 2016). Semi-structured interviews combine both fixed choice answering and the ability to go deep in the relevant field. It has such advantages as ease of analysis, ability to express oneself to the interviewee, and providing indepth information (Büyüköztürk, Çakmak, Akgün, Karadeniz, \& Demirel, 2008).

Semi-structured interview forms were prepared in this study to get the opinions of the participants. The interview forms prepared by the researcher were examined by two faculty members, who are the field specialist and a graduate classroom teacher. Some questions were rearranged in line with expert opinions. The questions in the interview form were supported with probe questions according to the flow of the interview. Through these probe questions, the participants were asked to detail their opinions. As a result, the obtained qualitative data were described by making direct quotations from the opinions of the participants.

Primary school 4th-grade students $(n=27)$ in the experimental group were asked for their opinions on the Collaborative Strategic Reading practice. The findings of the opinions obtained from the students are as follows.

In their thoughts on the Collaborative Strategic Reading studies conducted to teach the informative texts to the experimental group students, all of the students $(n=27)$ stated that they liked the studies 
and activities, that they facilitated the texts, and that they were useful, entertaining, and quite instructive. Some of the given answers $(n=7)$ were in the form of I love it, it was great, and it was perfect. Below are some examples of student opinions:

"I like this method because I enjoy studying with my friends in the group. (S5)"

"I loved it because everyone had a job, and we studied as a group, in collaboration. (S11)"

"I liked it because we had our previous Turkish lessons very normally. After this method, the texts became much more fun. (S8)"

"I liked it. I collaborated with my friends. I both had fun and learnt. (S10)"

"It was great because I understood the informative texts better thanks to our teacher. Anyway, when the lesson is loved, one inevitably understands it. (S17)"

When asked about their opinions on how to easily determine the main idea of the text when they read any informative text, all of the students ( $\mathrm{n}=$ 27) mentioned that they could determine the main ideas much more easily. Some examples of student opinions are as follows.

"I can determine it very comfortably because I initially determine the main idea on my own, and then we, as a group, discuss the main idea. Thus, a good main idea emerges. (S4)"

"Yes, I can determine it easily because we can answer the questions related to the main idea. I am very used to this method now. (S6)"

"I couldn't determine it alone before, but I can determine it right away because I can study with my group. (S13)"

"I couldn't determine it before, but thanks to the group, my ability to determine the main idea improved sentence by sentence. (S9)"

"I can determine it because the learning diaries and group study have made my job easier. (S17)."

The question "What did you gain by learning informative texts in this way, what are the benefits of this application for you?" was asked to the students; they stated that they learned information more easily $(\mathrm{n}=12)$, that this method provided more meaningful and enjoyable learning $(n=4)$, that they would be more successful in exams and tests $(n=4)$, that they understood the meaning of words more easily ( $\mathrm{n}$ $=4$ ), and that they gained the benefits of studying with groups. Below are some examples of student opinions.

"Reading texts in this way I learned is very useful because new information is understood more easily. It is more enjoyable. (S1)"

"Reading texts in this way is very useful because it gave me new knowledge. I can understand the texts more easily when I read them. (S3)"

"I have gained new knowledge, and I can find the meaning of the words that I do not know thanks to the method I have just learned. (S5)"

"Thanks to this study, I was able to understand the text by doing a group study with my friends. In this way, I learned better by doing group study. (S7)'

"Thanks to this method that I have just learned, my ability to determine the main idea has increased. I can now extract the meanings of unknown words from the text. (S19)"

In answer to another question, "whether they want to continue reading the informative texts they encounter from now on in this way," asked the experimental group of students, all of the students (n $=27$ ) expressed that they wanted to continue reading in this way. Some examples of student opinions are as follows.

"I would like to continue because studying with the group is both fun and instructive. (S4)"

"I desire it because there are too many texts that I do not know yet and that I expect to read. If I learn these texts the way our teacher showed us, I can understand them more easily. (S21)"

"Yes, I would; why? Because when I read the texts in this way, I can better visualise the events in my head. (S10)"

"I want it because the texts I read in this way stay in my mind more. (S16)"

Some students answered as no $(n=19)$, and some students answered as yes $(n=8)$ to the last question of the interview part, "do you have any thoughts to add?". Some of the answer examples of the students who said yes are listed below.

"I am very happy to learn with such a method and with you. I hope this activity will continue. (S2)"

"The thought I want to add is that I wish other teachers would apply this different way you applied to us in other lessons. (S15)"

"Yes, there is. Please do not change this activity 
at all. (S7)"

It can be stated that the opinions of the experimental group students about the Collaborative Strategic Reading Model are generally positive. In most of the answers, it was mentioned that the practice was fun, useful, and instructive and that studying in collaboration with the group contributed positively to them.

The first question directed to the classroom teacher is what the level of knowledge he has about the informative texts is and whether there is a different method he applies while lecturing these text types. The answer given by the classroom teacher is presented below.

"Initially, my prior knowledge of informative texts is based on my university years. Even though I have information from the presentation I prepared about informative texts in my university education, I have not lectured through any method, technique, or model specific to the informative texts in my professional life. In general, I make the students underline the information in the text that I consider important. Then I explain the content of the underlined information to the students through the presentation."

Another question asked to the classroom teacher of the experimental group is whether the activities and practices of the Collaborative Strategic Reading Model are beneficial for their students. The answer by the classroom teacher is shown below.

"I think it is very useful because, first of all, I witnessed my students studying very efficiently during group study. Seeing that there is a role given to each of my students made me happy even as a classroom teacher. As far as I observed, every student was active, and they were more creative together. We had not done any group study during these four years. In addition, I was also surprised not to hear the words of any of them that we were bored even though they were constantly tested before and after each activity. In general, I think the Collaborative Strategic Reading Model is very useful."

Another question of what are the positive and negative situations he observed during the practice were asked. The answer given by the classroom teacher is as follows.

"There are too many situations that I see positive about the practice. For instance, a role for each student, determining the main idea in a very different way, namely from part to whole, finding the words whose meaning is unknown from the sentence or paragraph, determining the interesting ideas in the text, preparing questions about the text through the different methods, and frequent use of in-group discussions. On the other hand, negatively, children can get a little too deep into talking to each other. In other words, I think the teacher should have good classroom control and should adopt the roles of the students very well."

The answer is given by the classroom teacher to the question "Do you intend to use the practices of the Collaborative Strategic Reading Model in Turkish or other lessons?" is provided below.

"Of course, I would like to use it because I think the learning experience that my students will have with fun, discussion, and cooperation is very valuable for my class. In my opinion, its effect on the Turkish lesson I observed, in particular, is indisputable. Still, I believe that it is necessary to think about how it can be applied in other lessons and to make new studies."

As a result, the classroom teacher of the experimental group thinks that the Collaborative Strategic Reading Model is very useful. He found it very useful in determining the main idea and word meaning way of the model, having ingroup discussions, and the quality of the questions prepared for different methods. The only criticism made by the classroom teacher is that there may be classroom management problems stemming from the collaboration of the model.

\section{Conclusion}

It is concluded in the relevant literature that there are some studies conducted with the Collaborative Strategic Reading Model. It is also seen that most of these studies originate from abroad. In our country, there is no study adapting the Collaborative Strategic Reading Model into primary school.

When the studies conducted with the Collaborative Strategic Reading Model generated by Klingner, Vaughn, and Boardman (1998) are examined, many examples emerge in the international literature. The first of these studies is the research of the developers 
of the model (Klingner et al., 1998) in terms of the use of the Collaborative Strategic Reading Model in the Social Studies course of primary school fourthgrade students. Within the scope of this study, fourth-grade students, including students with three different reading levels, were included. 85 students participated in the 11-day study implemented by the researchers. 56 of the participants were in the control group, and 29 were in the experimental group. As a result of the study, it was revealed that the students in the experimental group were much more successful in the reading comprehension test. Another study by Klingner et al. (2004), who developed the model, was published with the Effect of Classroom Teachers on "Real World" lessons through the Collaborative Strategic Reading Model. Within the scope of the study, a model in a more developed form was explained to the classroom teacher who carried out educational activities in five classrooms. When the classes that received the model training and the control group were compared, it was concluded that the experimental group was again more successful in reading comprehension tests. Likewise, in the last study by the developers of the model (Boardman et al., 2015), the effects of the Collaborative Strategic Reading Model on the Secondary School Social Studies course were examined. The study was conducted very wide, and 19 teachers and 1074 middle school students participated. The researchers firstly subjected 19 participating teachers to a series of training in which information about the Collaborative Strategic Reading Model was given and some practices were carried out. Even though the subject of the research is Social Studies, all of the texts used in the research are informative texts. As in other studies, the experimental group students who attended the lessons with the Collaborative Strategic Reading Model in small groups were successful in reading comprehension. In all the studies with the students of different classes and levels conducted by J. Klingner, S. Vaughn, A. Boardman, the developers of the model, through the Collaborative Strategic Reading Model, the experimental group students were more successful than the control group students. These results are similar to the findings obtained in this research.

The Collaborative Strategic Reading Model has been applied in many masters and doctoral dissertations abroad in which different age groups participate. One of these studies belongs to the master thesis by Nurhayati (2015) in Indonesia. The purpose of this study is to reveal the effectiveness of using the Collaborative Strategic Reading Model for fifth-grade students in understanding narrative texts. Within the scope of the study, experimental and control groups were included, and all of the 60 students that made up the sample were secondary school first-year students. After pre-tests were applied to the experimental and control groups in the study, whereas the experimental group students had their lessons with the Collaborative Strategic Reading Model, the students in the control group were taught through the classical curriculum. As a result of the post-tests performed after the practice was completed, it was concluded that the Collaborative Strategic Reading Model was effective in understanding the narrative texts. The mean score of the experimental group was 25,50 in the post-test, the mean of the control group remained at 14,50. In his master thesis in Thailand, Rattanasaeng (2011), who carried out another study, tried to determine the effect of the model on reading comprehension by reading electronic books for children used in the fifth grade of primary school through the Collaborative Strategic Reading Model. In this context, 32 students participated in the study conducted in the 2011-2012 academic year.

Learning diaries, reading ability tests, and content analysis was implemented in the research. As a result of the research, the researcher confirms that the teaching through the Collaborative Strategic Reading model positively affects the reading comprehension ability of the students with a mean score of 86,37. In a doctoral dissertation, including another study for the fifth grade, McCown (2013) examined the effects of the Collaborative Strategic Reading Model on the reading comprehension of the primary school fifth-grade students for informative texts and their metacognitive awareness. The possible effects of the Collaborative Strategic Reading Model by using the Reading Inventory-5 (QRI-5) and Competence Test (CRCT) developed on informative text comprehension were examined in this study, which utilises a quasi-experimental, pre-test and post-test 
control group design. In addition, the metacognitive awareness of the participants was measured by using the Reading Strategies Inventory (MARSI). In the study results, a significant difference was obtained through Mancova analysis, indicating that the experimental group was better than the control group in understanding the informative texts. Considering the results of all these theses (Nurhayati, 2015; Barberio, 2005; Rattanasaeng, 2011; McCown, 2013), it was concluded that the pre-test and posttest control group design was used and that the experimental group using the Collaborative Strategic Reading Model was more successful. These results are also similar to the results of this research.

When the thesis studies conducted with mixedmethod and the Collaborative Strategic Reading Model are examined, it is observed that the first of these studies is the master study by Seacrist (2012) in the United States. The study purposes of examining the six fourth grade students who have problems in learning. Within the scope of the research, students who had difficulties in learning were gathered in a single classroom, and some exercises were conducted according to the Collaborative Strategic Reading Model for 5 weeks. As a result of the study, an increase was determined in the mean scores of the students for reading comprehension and vocabulary. However, despite the increase in the mean scores, it was determined in the observation study that classroom management was inconsistent with this increase. According to this result, it can be stated that the students who have difficulties in learning need more time to adopt the group study or collaborative comprehension strategies. The result of this qualitative study is consistent with the result of this study. In a study conducted by Shin (2009) with the primary school first-grade students in the United States of America, it was explained how the Korean students learning English learn and interact by applying the Collaborative Strategic Reading Model to reading comprehension teaching. Signal cards were used during the analysis, and all techniques of the Collaborative Strategic Reading Model were explained and applied to the students. As a result of the qualitative study, all students stated that they liked the techniques applied to them during the practice process. Also, it was assumed in this study that the
Korean participants might not have fully developed the objectives of the model because it is difficult to learn English for them and the primary school firstyear students do not have the necessary cognitive academic knowledge and vocabulary for reading comprehension. However, it was concluded in the observation technique that the learning speed of the students who applied the model was positive in the compared English learning speeds. A different study with the mixed method is the thesis study conducted by Rosalina (2014) in Indonesia. Within the scope of the study, the empirical evidence of the effect of using the Collaborative Strategic Reading Model was tried to be determined to measure the success of secondary school sixth-grade students in reading comprehension for the informative texts. Thus, it was purposed to obtain reliable data on whether there is a significant difference in the reading comprehension scores of the students between the experimental class and the control class. Whereas the mean score of the experimental group was 82,20 , the mean score of the control group was 64,57. Moreover, it was concluded in the qualitative interviews that the Collaborative Strategic Reading Model is very useful. Therefore, it is accepted that the Collaborative Strategic Reading Model affects the student achievement in understanding the informative texts.

The studies likely to be exemplified are not only at primary, secondary, or high school level. A doctoral dissertation was applied by Al-Roomy (2013) in the USA. Within the scope of the study, the ways to improve the reading comprehension skills of Saudi students at the medical school at a university continuing their education in the USA were examined. In the doctoral dissertation, initially, the difficulties of Saudi students in teaching, learning and reading English were analysed. As a result, an action was planned based on the Collaborative Strategic Reading Model, and this plan was applied to other students as a pilot study. As a result of the actual research conducted after the pilot study, it was obtained that the Collaborative Strategic Reading Model enabled Saudi medical school students to significantly improve their reading comprehension. The findings also concluded that reading comprehension through group study and applying it by combining it with exploratory speaking is more 
beneficial.

Similarly, Yen (2009) conducted another doctoral dissertation study with Taiwanese university students at Leicester University in the UK. The English level of 110 university students participating in the study is intermediate. In the study, the mixed method with pre-test and post-test control groups was adopted, and some interviews were conducted with the students as qualitative research. It was concluded that the experimental group students who learned English through the Collaborative Strategic Reading Model understood what they read better and were more successful in determining the main idea. The findings also indicate that Taiwanese university students with limited vocabulary also improved after applying the Collaborative Strategic Reading Model. According to the qualitative research results, it was determined that the students developed a positive attitude towards the model. The results of these two doctoral dissertations (Al-Roomy, 2013; Yen, 2009) conducted with university students also show similarities with the results of this research.

When the articles in the literature on which the Collaborative Strategic Reading Model are applied are examined, similar results are seen with the thesis studies mentioned above. Firstly, in the study conducted by Sari and Tamah (2015), two groups were obtained from middle school sixthgrade students. The group that received training with the Collaborative Strategic Reading Model was more successful in understanding what they read than the group that received teacher-centred education. In another study conducted by Septiani and Eliwarti (2017), it was examined to what extent the reading comprehension skills of primary school first-grade students developed with the help of the Collaborative Strategic Reading Model. As a result, it was determined that the Collaborative Strategic Reading Model had significant effects on the reading comprehension skills of the first-grade students.

67 students participated in the study conducted by Sofyan et al. (2015) with high school students. As a result of the study, it was concluded that the experimental group students in the reading comprehension studies conducted while learning a second language through the Collaborative Strategic Reading Model were more successful in the reading comprehension test than the control group. Besides, it was observed that the opinions of more than 80 per cent of the students regarding the in-class practices of the Collaborative Strategic Reading Model were very positive. 40 Iranian students studying in the English Language and Literature department participated in the study conducted by Khonamri and Karimabadi (2015) with the students of Mazandaran University. T-test was applied to analyse the pre-test and posttest results of the experimental and control groups, and it was ensured to check whether there was a significant difference between the performances of the students according to their critical reading skills. As a result, it was concluded that the students in the experimental group, who received training through the Collaborative Strategic Reading Model, left behind the students in the control group.

According to the findings of this study, teaching the informative text through the Collaborative Strategic Reading Model positively affects the reading comprehension and main idea determination skills of primary school fourth-grade students. The following recommendations have been developed in line with this result:

- The teachers should not choose informative texts that are difficult for their students to understand while reading. In addition, when choosing the texts to be processed, the structural features of the text should be checked, and good examples of their type should be selected.

- The courses on processing the informative texts can be given to pre-service teachers in Education Faculties. In addition, reading comprehension strategies can be explained with the help of in-service and out-of-service training for the teachers who start their duty.

- If the teachers often use reading comprehension strategies in their courses, the students can also be strategic readers at any moment of their lives.

- In-text studies, activities should be made to determine the main ideas and supporting ideas that are frequently included in the text. Making use of reading comprehension strategies while determining main ideas and supporting ideas can facilitate the process.

- While processing informative text structures, students can be taught and applied reading 
comprehension strategies other than the Collaborative Strategic Reading Model (KWL; Think Before, During, and After Reading Strategy; Process Model Strategy, etc.).

- In this study, the courses were taught to the class that constitutes the control group by the Turkish lesson Education Program, which constitutes the traditional teaching methods. In further studies, the courses can be taught according to a different reading comprehension strategy for the control group, and a new practice can be done.

- In the qualitative method-based interview technique performed in this study, the classroom teacher of the experimental group stated that the problem occurred while applying the Collaborative Strategic Reading Model. That classroom management was difficult at the time of practice. Based on this opinion, classroom management seminars can be given to classroom teachers for group study. As another solution, it can be ensured that the students follow and adopt the rules of studying together with the group by doing group activities with the students frequently.

- This study was conducted with primary school fourth-grade students with a normal reading level. The effectiveness of the model can be examined with the students who have different reading levels or are at a different grade.

- To introduce the Collaborative Strategic Reading Model to a wider audience, books can be published about the method practices of the model and about how the model should be applied, a website can be prepared on the internet, or inservice seminars can be provided to the teachers.

- that deal with the differentiation in the use of digital technologies. In addition, in theories such as the technology acceptance model proposed by Davis (1989), individuals and individual characteristics are highlighted in the difference in the use of technology.

\section{References}

Al-Roomy, Muhammad. An Action Research Study of Collaborative Strategic Reading in English with Saudi Medical Students. University of Sussex, 2013.
Balc1, Ahmet. Okuma ve Anlama Eğitimi. Pegem Academi Publications, 2016.

Barberio, Inez Lee. The Effects of Collaborative Strategic Reading among Third Grade Students. Rowan University, 2005.

Boardman, Alison G., et al. "The Efficacy of Collaborative Strategic Reading in Middle School Science and Social Studies Classes." Reading and Writing, vol. 28, 2015.

Bryan, G., et al. "Why Children Choose the Books that they Choose." Academic West CAST Conference, 2007.

Büyüköztürk, Şener. Sosyal Bilimler Için Veri Analizi El Kitabı. Pegem Academi Publications, 2016.

Büyüköztürk, Şener, et al. Bilimsel Araştırma Yöntemleri. Pegem Academi Publications, 2016.

Büyüköztürk, Şener, et al. Bilimsel Araştırma Yöntemleri. Pegem A Publications, 2008.

Creswell, John W. Research Design: Qualitative, Quantitative, and Mixed Methods Approaches. Sage Publications, 2003.

Fan, Yen-Chi. Implementing Collaborative Strategic Reading (CSR) in an EFL Context in Taiwan. University of Leicester, 2009.

Karasar, Niyazi. Bilimsel Araştırma Yöntemi. Nobel Publications, 2011.

Khonamri, Fatemeh, and Maedeh Karimabadi. "Collaborative Strategic Reading and Critical Readingability of Intermediate Iranian Learners." Theory and Practice in Language Studies, vol. 5, no. 7, 2015.

Klingner, Janette K., et al. "Collaborative Strategic Reading: "Real-World" Lessons from Classroom Teachers." Remedial and Special Education, vol. 25, no. 5, 2004, pp. 291-302.

Klingner, Janette K., et al. Now We Get It: Boosting Comprehension with Collaborative Strategic Reading. Jossey-Bass Publishing, 2012.

Klingner, Janette K., et al. "Collaborative Strategic Reading during Social Studies in Heterogeneous Fourth-Grade Classroom." The Elementary Journal, vol. 99, no. 1, 1998, pp. 3-22.

McCown, Margaret Averill. The Effects of Collaborative Strategic Reading on Informational Text Comprehension and 
Metacognitive Awareness of Fifth Grade Students. Liberty University, 2013.

Nurhayati, Dede. The Effectiveness of Using Collaborative Strategic Reading on Students Reading Comprehension of Narrative Text. State Islamic University, 2015.

Rattanasaeng, Kanpajee. The Development of Collaborative Strategic Reading (CSR) Instruction Using Electronic Children's Picture Books for Fifth Grade Students. Chulalongkorn University, 2011.

Repaskey, Lisa L., et al. "First and Fourth Grade Boys' and Girls' Preferences for and Perceptions about Narrative and Expository Text." Reading Psychology, vol. 38, no. 8 2017, pp. 808-847.

Rosalina, Anike. The Influence of Collaborative Strategic Reading (CSR) Technique on Students' Achievement in Reading Comprehension of Narrative Text. Syarif Hidayatullah State Islamic University, 2014.

Sari, Carolin Diana, and Siti Tamah. "The Effect of
Collaborative Strategic Reading on Grade Six Students' Reading Achievement." Indonesian Journal of English Education, vol. 2, no. 1, 2015, pp. 17-27.

Seacrist, Kathy. The Effect of Collaborative Strategic Reading for 4th Graders with Learning Disabilities. Rowan University, 2012.

Septiani, Riri, and Dra Eliwarti. "The Effectiveness of Collaborative Strategic Reading (CSR) towards the Reading Comprehension of the First Grade Students of SMA N 14 Pekanbaru." Journal Online Mahasiswa Fakultas Keguruan dan Ilamnu Pendidikan, vol. 4, no. 1, 2017.

Shin, Mikyung. The Interactive Behaviors and Perceptions of Korean English Language Learners in Collaborative Strategic Reading. West Texas A\&M University, 2009.

Gani, Sofyan A., et al. "Progressive Outcomes of Collaborative Strategic Reading to EFL Learners." Kasetsart Journal of Social Sciences, vol. 37, no. 3, 2016, pp. 144-149.

\section{Author Details}

Muhammed Serhat Semercioglu, Gumushane University,Turkey,Email ID: segusem@hotmail.com.

Kaya Tuncer Çağlayan,Turkey, Email ID: ktuncerc@omu.edu.tr.

Kasım Kıroğlu, Turkey, Email ID: november@omu.edu.tr. 